\title{
Antecedents of Participation in Physical Activity among Generation $Y$ at a South African Higher Education Institution
}

\author{
R Nishimwe-Niyimbanira
}

School of EconomicSciences, North-West University, Vanderbijlpark, South Africa.

Email:24720992@nwu.ac.za

PF Muzindutsi

School of Economic Sciences, North-West University, Vaal Campus, Vanderbijpark, South Africa.

Email:24754293@nwu.ac.za

\section{Doi:10.5901/mjss.2014.v5n21p291}

\begin{abstract}
Physical activity has crucial health benefits for individuals of all ages. This study aimed at determining the prevalence of physical activity and its determinants among generation $Y$ students. This study followed a quantitative research design through a self-administered survey questionnaire. Data was collected from a sample of 540 undergraduate students randomly selected from a South African university. The short version of the International Physical Activity Questionnaire (IPAQ), which measures physical activity by self-report over the previous 7 days, was used to measure the prevalence of physical activity. Data analysis involved the use of various statistical techniques such descriptive statistics, correlation and regression analyses. Results showed that $36 \%$ of students engaged in low physical activity; while $45.3 \%$ and $18.3 \%$ engaged in moderate and in high physical activity, respectively. Correlation analysis showed a significant association between prevalence of physical activity and two dimensions (physical exertion and time expenditure) of perceived barriers of physical activity. Regression results revealed that students' participation in physically is mostly influenced by gender, means of transport to or from school, year of studies, physical exertion and time expenditure. Findings of this study point to a need of intervention programs promoting positive attitude towards participation in physical activity among South African university students.
\end{abstract}

Keywords: physical activity, health benefit, perceived barriers, Generation Y, South Africa

\section{Introduction}

Physical activity has crucial health benefits for individuals of all ages. Physiological and psychological benefits of regular sports activities are well documented (Shoji, Hamada \& Mano, 2013). Participation in physical activity has been associated with more favourable biological cardiovascular diseases, risk-factor profiles (such as lower blood pressure, decreased adiposity, and more favourable serum lipid and lipoprotein levels) and psychological health, such as greater levels of self-esteem and lower levels of stress and anxiety (Brown \& Siegel, 1988; Dietz, 1998; Thijssen, Maiorana, O'Driscoll, Cable, Hopman \& Green, 2010). Regular physical activity is therefore considered as the main element of healthy lifestyle. Studies in epidemiologic field have revealed that physically active persons live longer than those who are sedentary (Paffenbarger, Hyde, Wing, Lee, Jung \& Kampert, 1993; Kaplan, Strawbridge, Cohen \& Hungerford, 1996; Kujala, Kaprio, Sarna \& Koskenvuo, 1998). The concept of physical activity involves the full variety of human movement, such as competitive sports and exercise, active hobbies, cycling or any other physical activities of daily living (Caspersen, Powell \& Christensen, 1985; Riddoch, 2005). The level of participation in these activities may varies across the age groups or generations (Allman-Farinelli, Chey, Merom, Bowles \& Bauman, 2008).

The main purpose of this study is to investigate the antecedents of participation in physical activity among generation $\mathrm{Y}$. A generation refers to a group of people born in the same era, shaped by the same times and influenced by the same social markers (McCrindle \& Wolfinger, 2008). Generation Y among others (such as Traditionalists, Baby Boomers, Generation X and Z) includes individuals born between the late 1970s and the late 1990s (Princetonone, 2008). Generation $Y$, also known as Millennials or Echo Boomers, presents particular features from some perspectives in the framework of this study. This is the first generation from birth that has been surrounded by digital products driven by technology developments (Yarrow \& O'Donnell, 2009). Ravussin (1995) argued that individuals born in after late 1970s entered a high-tech society with few demands on physical activity. Baby boomers and earlier generations were born into 
a world before the television, computer, widespread motor vehicle usage and other digital products and their everyday physical activity energy expenditure was probably greater that of generation $Y$ (Allman-Farinelli et al., 2008). Among generation $Y$ there is a vast increase in reliance upon technology results in more time being spent indoors, being less physically active (Sotade, 2012).

Longer working hours could also provide another explanation of fewer opportunities for physical activity among generation $\mathrm{Y}$. In their study on the effects of age, birth cohort and survey period on leisure-time physical activity by Australian adults, Allman-Farinelli et al. (2008) found that younger Australians are increasingly more physical inactive than their precursors, with less time spent in physical exercise than individuals of retirement age. The same pattern was found among Generation $Y$ males where their prevalence of physical exercise was far less than preceding generations was at the same age. This generation dominates workplace and presents the largest demographic cohort when compared to other generations (Johnson Controls, 2010). Hence, its higher prevalence of physical inactivity, as it associated with numerous health harms, would be a threat to the world.

In addition to dominating the work place, generation $\mathrm{Y}$ also dominate the current population of university students (Johnson Controls, 2010). Reviewing 19 studies from 27 countries on university students' participation in physical, Irwin (2004) found that more than one-half of university students in the United States and Canada were not active enough to gain health benefits. In all studies reviewed by Irwin (2004), only Australian students made an exception of having the highest level of sufficient physical activity. In the South African context, Pengpid and Peltzer (2013) found a high prevalence of low physical activity (33\%) among students of Limpopo University. Furthermore, Bloemhoff (2010) found the same level of physical inactivity (33\%) among undergraduate students in University of the Free State. Therefore, both international and South African studies tend to suggest that the majority of university students appear to be insufficiently physically active.

The analysis of why people do not participate in physical activity is controversial and multidimensional and covers personal, interpersonal, demographic, socio-economic, physical environments, academic commitment and cultural factors (Lovell, Ansari \& Parker, 2010). Perceived benefits and barriers to physical activity have been found to be one of the predictors of physical activity. In their study, Sallis, Prochaska and Taylor (2000) found that individuals who perceived few barriers and more benefits presented a higher likelihood of becoming physically active than those who perceived few benefits and more barriers. Barriers to participation in physical exercises are mostly classified into factors related to exercise environment, time expenditure, physical exertion and family discouragement (Sechrist, Walker \& Pender, 1987, Brown, Pfeiffer, Mclver, Dowda, Almeida \& Pate, 2006). Beside the effect of the perceived barriers, prevalence of physical activity is also influenced by cultural, demographic and socio-economic factors (Haase, Steptoe, Sallis, \& Wardle, 2004). The age and gender were found to be the most consistent demographic factors determining barriers to physical activity (Godin, Desharnais, Valois, Lepage, Jobin \& Bradet, 1994; Trost, Owen, Bauman, Sallis, \& Brown, 2002; Brown, 2005); where male people, in general, tend to be more active than female (Trost et al., 2002). Concerning socioeconomic factors, a positive relationship between participation in physical activity and income (Scheerder, Thomis, Vanreusel, Lefevre, Renson, Vanden Eynde \& Beunen, 2006) and education (Thornórarinsson, Harðarson, Sigvaldason \& Sigfússon, 2002; Shaw \& Spokane, 2008) have been found.

In addition to the aforementioned factors, academic commitment among other factors has been found to be one of key factors affecting generation Y students' perceptions vis-á-vis participation in physical activity. In a study, conducted in Metropolitan Toronto School District by Zunft, Friebe, Seppelt, Widhalm, Remaut de Winter, Vaz de Almeida, Kearney and Gibney (1999), participants considered school work and family activities as key barriers to participation in physical activity. In a Spanish university, the lower prevalence of physical activity was found in humanities, education sciences and arts students compared to health sciences students (Varela, Ayán, Cancela, Martín, 2012). Eyler, Baker, Cramer, King, Brownson and Donatelle (1998) found involvement in physical activity to be often encouraged by family and friend. However, this may not always be the case. Sallis (1999) argued that if an adolescent (such as a student) belongs to a peer group that values and participates in physical activity, the group creates a supportive environment for its members. If the main peer group devalues physical activity, this is an effective deterrent; thus the peer group is regarded as barrier that inhibits participation in physical activity.

Few studies investigating physical activity among generation $Y$ in Africa exist and this calls a need of identifying factors discouraging the participation in physical activity among this group. This identification of factors limiting the participation physical activity can assist in designing and implementing effective physical activity promotion programs to deal with physical inactivity among generation $Y$ which constitute the largest proportion of population worldwide. Therefore, this study aimed to determine the prevalence of physical activity among generation $Y$ students and explore the relationship between the perceived barriers to physical activity and actual participation in physical activity. 


\section{Methodology}

\subsection{Research Instrument}

This study used a quantitative research design through a self-administered survey questionnaire. The International Physical Activity Questionnaire (IPAQ) was the instrument used to assess the prevalence of physical activity among generation Y. This study used the 9 item short form of IPAQ which is self-report of physical activity over the previous 7 days (Craig, Marshall, Sjostrom, Bauman, Booth, Ainsworth, Pratt, Ekelund, Yngve, Sallis \& Oja, 2003). The items in the short IPAQ form were structured to provide separate scores on walking, moderate-intensity and vigorous-intensity activity. Computation of the total score for this form requires summation of the duration (in minutes) and frequency (days) of walking, moderate-intensity and vigorous-intensity activities. Data collected with IPAQ can be reported as a continuous or categorical measure. One measure of the volume of activity can be computed by weighting each type of activity by its energy requirements defined in METs to yield a score in MET-minutes. A MET-minute is computed by multiplying the MET score of an activity by the minutes performed. The IPAQ Research Committee (2005) suggested the values of MET as follows: Walking $=3.3 \mathrm{METs}$, Moderate physical activity $=4.0 \mathrm{METs}$; Vigorous physical activity $=8 \mathrm{METs}$. Three categories of physical activity (low, moderate and high), as suggested by the IPAQ Research Committee (2005) short form, were used in this study. Low category represented individuals who not meet criteria for two remaining categories (moderate and high). Moderate activity represented moderate-or vigorous -intensity activities achieving a minimum of at least $600 \mathrm{Met}-\mathrm{min} /$ week. High activity represented achieving a minimum of at least $3000 \mathrm{Met}-\mathrm{min} /$ week (IPAQ Research Committee, 2005; Bauman, Bull, Chey, Craig, Ainsworth, Sallis, Bowles et al., 2009).

\subsection{Sample}

A random sample of 540 undergraduate students was selected from North-West University, Vaal campus in the Gauteng province of South Africa. More than a half of participants were female students (53.6\%); while the remaining $46.4 \%$ were male. The mean age of the participants was 19.88 ( $S D=2.04$ ) years. About $44 \%$ of students reside on campus, while the off-campus students account $56 \%$. Racial distribution of sampled population showed that the majority (78.2\%) of students were Africans; while other races (White, Indians/Asians and Coloured) shared the remaining 21.8\%. First year students counted for $53 \%$ of participants, while the remaining $47 \%$ were senior undergraduate students. In terms of the faculty, $64 \%$ of the participants belonged to the faculty of commerce, while the remaining $36 \%$ was from the faculty of humanity studies. The majority of the students (72\%) use cars to school, while $28 \%$ walk or cycle to school.

\subsection{Model specification}

One of the purposes of this study was to identify the main factors which determine an individual's probability of being found in a specific physical exercising stratum (physical active and physical inactive). The regression model was used to achieve this objective. Participants were categorised into two categories. Participants who presented a low prevalence of physical activity were considered to be physically inactive, while those who had moderate and high prevalence of physical activity were considered to be physically active (Bauman et al., 2009). The dependent variable ( $\mathrm{y}_{\mathrm{i}}$ ) for the logistic regression is taken as a binary variable with:

$y_{i}=1$, for physically active individual, and

$y_{i}=0$, otherwise

Explanatory variables were socio-demographic, personal and other different aspects of an individual and involve a combination of dummy and continuous variables. The model used in this study to estimate the determinants of participation in physical activity is as follows:

$Y_{i}=\beta_{0}+\beta_{1} X_{1}+\beta_{2} X_{2}+\beta_{3} X_{3}+\beta_{4} X_{4}+\beta_{5} X_{5}+\beta_{6} X_{6}+\beta_{7} X_{7}+\beta_{8} X_{8}+\beta_{9} X_{9}+\beta_{10} X_{10}+\beta_{11} X_{11}+u_{i}$

Where $Y_{i}$ stands for physical activity status for a participant (1 if a participant is physically active and 0 otherwise); $X_{1}$ is the age of a participant; $X_{2}$ is the dummy for the gender of a participant (1for male and 0 for female); $X_{3}$ is the dummy for the participant's race ( 1 for Black and 0 for otherwise); $X_{4}$ is the dummy for the mode of transport to/from school ( 1 for using a private or public car, and 0 for walking or cycling); $X_{5}$ is the dummy for the place of residence while at school ( 1 if a participant stays on campus and 0 otherwise); $X_{6}$ is the dummy for the faculty ( 1 for commerce and 0 for humanity studies); $X_{7}$ is the dummy for the year of study ( 1 if a participant is a first year student and 0 otherwise). The barriers to physical activity covering personal, environmental, social and interpersonal aspects were represented by physical exertion $\left(X_{8}\right)$, exercise milieu $\left(X_{9}\right)$, time expenditure $\left(X_{10}\right)$ and family discouragement $\left(X_{11}\right)$. The elements in $\beta$ 
(from $\beta_{1}$ to $\beta_{11}$ ) are slope parameters to be estimated, $\beta_{0}$ is the intercept and $u_{i}$ is an error term.

The 4 variables of barriers to physical activity are sub-scales of perceived barriers to physical activity scale developed by Sechrist et al. (1987). The barrier scale combines 14 barrier items categorised into four dimensions, namely physical exertion ( 3 barrier items), exercise milieu ( 6 barrier elements), time expenditure ( 3 barrier items) and family discouragement (2 barrier items). Each item is rated on a four-point Likert scale ranging from strongly agree (1) to strongly disagree (4) and the mean score was used generate index for each sub-scale. Test for internal consistency showed that Cronbach's a of the overall barrier scale was 0.92 , while Cronbach's a of the 4 subscales of barrier scale were between 0.88 and 0.93 , showing a strong reliable measure.

\section{Results and Discussion}

\subsection{The prevalence of physical activity among participants}

Table 1 depicts categorical results according to different aspects of the participants. The results indicates that $36 \%$ among Generation $Y$ in a South African higher institution engaged in low level of physical activity, $45.3 \%$ engaged at moderate level and $18.3 \%$ in high level. These findings are in a similar range as those of Bloemhoff (2010) and Pengpid and Peltzer (2013) who found the prevalence of low physical activity to be 33\% among undergraduate students of University of Free State and University of Limpopo in South Africa. Internationally, this case of high prevalence of physical inactivity was found by a number of studies (Irwin, 2004; Haase et al., 2004; Keating, Guan, Pinero \& Bridges, 2005). These findings highlight the low level of physical activity among generation $Y$. This low level of prevalence of physical activity may be linked with negative attitude which eventually leads to a low motivation of participating in physical activity. Thus, intervention programs promoting positive attitude towards physical activity among generation $Y$ students are necessary.

Table 1: The prevalence of physical activity within various variables

\begin{tabular}{|c|c|c|c|c|c|}
\hline & & Total sample & Prevale & f physical a & $(\%)$ \\
\hline & & $\mathbf{N}(\%)$ & High & Moderate & Low \\
\hline & & & & & \\
\hline Age & $\leq 18$ & $129(23.9)$ & 18.8 & 46.0 & 35.2 \\
\hline & $19-20$ & 217 (40.2) & 18.4 & 45.2 & 36.4 \\
\hline & $22-23$ & $162(30.0)$ & 18.5 & 45.4 & 36.1 \\
\hline & $24-25$ & $23(4.2)$ & 18.0 & 44.1 & 37.9 \\
\hline & $>25$ & $6(1.7)$ & 18.6 & 45.6 & 35.8 \\
\hline Gender & Male & $251(46.4)$ & 20.3 & 49.8 & 29.9 \\
\hline & Female & $289(53.6)$ & 17.0 & 41.5 & 41.5 \\
\hline Race & Black & 442 (78.2) & 18.3 & 44.8 & 36.6 \\
\hline & Non-black & $118(21.8)$ & 18.6 & 45.7 & 35.7 \\
\hline Transport to \& from & Private/public car & $389(72)$ & 17.9 & 43.8 & 38.3 \\
\hline school & Walking/cycling & $151(28)$ & 18.6 & 45.6 & 35.8 \\
\hline Place of residence & On-campus & 238 (44) & 18.3 & 44.9 & 36.8 \\
\hline & Off-campus & $302(56)$ & 18.2 & 44.7 & 37.1 \\
\hline Field of Studies & Commerce & $346(64)$ & 18.7 & 45.7 & 35.6 \\
\hline & Humanity & $194(36)$ & 18.6 & 45.5 & 35.9 \\
\hline Year of study & First year students & $286(53)$ & 19.1 & 46.7 & 34.2 \\
\hline & Senior students & 254 (47) & 17.9 & 43.7 & 38.4 \\
\hline
\end{tabular}

\subsection{Perceived barriers of physical activity and participation in physical activity}

Correlation analysis was used to examine the relationship between perceived barriers to physical activity and the actual physical activity of participants. As indicated in Table 2, there is a statistically significant negative relationship between the overall perceived barriers and participation in physical activity. Reviewing correlates of physical activity of children and adolescents, Sallis et al. (2000), also found a statistically significant inverse association between perceived barriers and participation in physical activity. There is a highly significant (at the $1 \%$ level of significance) negative association between involvement in physical activity and barriers of physical exertion $(-0.523)$ and time expenditure $(-0.367)$. Additionally, a weakly significant negative correlation (at the $10 \%$ level of significance) was found between barriers of 
family discouragement and participation in physical activity; while the negative relationship between participation in physical activity and barriers of exercise milieu appeared to be non-significant. These findings suggest that the actual involvement in physical activity is associated with the barriers of physical exertion and time expenditure, while there is no association between barriers of exercise milieu and involvement in physical activity. However, this existence of correlation does not imply the cause and effect between these variables. Hence, regression analysis was used to test the effect of various factors on participation in physical activities.

Table 2: Correlation between prevalence and perceived barriers to physical activity

\begin{tabular}{cccccc}
\hline & Overall barriers & Physical Exertion & Exercise Milieu & Time Expenditure & Family Discouragement \\
\hline Physical activity: Corr. & -0.297 & -0.523 & -0.097 & -0.367 & -0.185 \\
Sig. (P-values) & 0.016 & 0.000 & 0.121 & 0.007 & 0.098 \\
\hline
\end{tabular}

\subsection{Regression analysis}

The results of the binary logistic regression (in Table 2) suggest that the status of physical activity among Generation $Y$ students is mostly influenced by gender, means of transport to/from school, year of study, physical exertion and time expenditure. The coefficients of gender, transport to/from school and physical exertion are statistically significant at the $1 \%$ level of significance; while the coefficients of the year of studies and time expenditure are statistically significant at the $5 \%$ level of significance. All these variables appeared to have a significant influence on self-reported participation in physical activity.

Table 3: Regression results

\begin{tabular}{lccc}
\hline Explanatory variables & Beta & Std. Error & Sig. (P-values) \\
\hline Age(X1) & 0.102 & 0.097 & 0.210 \\
Gender (X2) & 0.217 & 0.032 & 0.000 \\
Race (X3) & -0.112 & 0.063 & 0.076 \\
Transport to and from school (X4) & 0.174 & 0.027 & 0.006 \\
Current residence (X5) & -0.021 & 0.012 & 0.364 \\
Faculty (X6) & 0.013 & 0.098 & 0.781 \\
Year of study (X7) & -0.132 & 0.046 & 0.031 \\
Physical Exertion(X8) & -0.189 & 0.029 & 0.003 \\
Exercise Milieu(X9) & 0.011 & 0.012 & 0.349 \\
Time Expenditure(X10) & -0.163 & 0.053 & 0.026 \\
Family Discouragement(X11) & -0.137 & 0.087 & 0.134 \\
\hline
\end{tabular}

Gender of the student is statistically significant $(p=0.000)$ with a positive sign $(0.217)$; implying that being a male, as compared to being a female, increased the probability of being physically active. This finding is in line with many studies which found that male participants were generally found to be more physically active than female (Bloemhoff, 2010, Santos, Silva, Santos, Ribeiro \& Mota, 2008; Martínez-Lemos, Puig-Ribera \& García-García, 2014; Salmon, Owen, Bauman, Schmitz \& Booth, 2000; Leslie, Owen, Salmon, Bauman, Sallis, \& Kai Lo, 1999). The coefficient of age was found to be non-significant determinant of physical activity in this study. This is in contrary to other studies (Godin et al., 1994; Trost et al., 2002; Brown, 2005) which found the age of participants to be a significant determinant of participation in physical activity. Due the fact that this study used a sample of generation $Y$ students with low level of variation in age (between 18 and 25) might be the plausible explanation for this finding. Previous studies, with a relatively higher variation in participants' age (King, Castro, Wilcox, Eyler, Sallis \& Brownson, 2000; Brownson, Eyle, King, Brown, Shyu \& Sallis, 2000), found a negative relationship between participation in physical activity and age. Additionally, Sallis (1999) argued that biologically, the increase in age among adult people should lead to increased drop out of vigorous exercise programs because of musculoskeletal injuries. Coefficient of race showed a weakly significant effect $(p=0.07)$ with a negative sign (0.112); implying that being an African compared to a non-black, decreased the probability of being physically active. This finding is consistent with that of Dunn and Wang (2003), while it does not support that of Bloemhoff (2010) who found that black students demonstrated higher levels of physical activity than their white counterparts.

After reviewing almost 45 studies about the correlates of adults' participation in physical activity, Trost et al. (2002) suggested more research to investigate if there is a difference in physical activity among people who use different means 
of transport. This is rationale for the inclusion of the mode of transport among variables tested in the current study. The coefficient of the mode of transport was found to be statistically significant $(p=0.006)$ with a negative sign $(-0.174)$. This implies that using public and private car compared to walking and cycling to/from school decreased the probability of being physically active.

Regression results also showed that the current residence and the faculty of a participant did not influence the participation in physical activity. These findings are contrary to those of Irwin (2004) and Pengpid and Peltzer (2013) who found that students living off-campus are more active than those who live on-campus. Contrary to our findings,Varela et al. (2012) also found a lower prevalence of physical activity among students who study humanities, education sciences and arts in comparison to those who are in health sciences. The year of study was found to have a significant influence on participating in physical activity, implying that being a first year, compared to second/third year student decreased the probability of participating in physical activity. These findings support that of Pengpid and Peltzer (2013) who found a lower prevalence of physical activity among first year students compared to second and third year students. Since this study was conducted in early the first semester, these findings may suggest that first students tend to compromise their participation in physical exercise during the time of adjusting to the new university's environment.

Perceived barriers to physical activity emerged as strong determinants of participation physical activity. Physical exertion and time expenditure were found to decrease the probability of being physically active. This supports Barrows' (2003) findings which showed that lack of time and tiredness were significant predictors of participation in exercises among American college students. Sallis (1999) also found the lack of time to be the most and common reason of physical inactivity. In many cases, students move away from their families and are exposed to academic and social commitment which increases the responsibility. In return, the high level of responsibility decreases the possibility of practicing in physical activity. As for the physical exertion, the results indicate that there is a need of intervention programs promoting positive attitude towards physical activity among university students.

Considering that the present study found a low level of participating in physical activities among generation $Y$ students in South African higher education institution, one should point out its possible limitation of relying on the use on self-reported physical activity which may sometimes result in an overestimation of behaviours considered positive. However, this should not be a major concern as the self-reported assessment of physical activity remains the most feasible and affordable instruments for global surveillance of physical activity.

\section{Conclusion}

Physical activity has crucial health benefits for individuals of all ages. A large number of people in the world are aware of benefits of regular physical activity in combination with healthy lifestyle but one of the key problems the worldwide health faces is low fitness levels. This study gained further understanding on the prevalence of physical activity and its determinants among generation Y. A high prevalence of physical inactivity found among Generation $Y$ students calls for strategic intervention by relevant professionals in higher educational institutions as suggested. This intervention will need to give a special attention to the specific groups of students (such as female and first years) who reported a low prevalence of physical activity.

\section{References}

Allman-Farinelli, M., Chey, T., Merom, D., Bowles, H., Bauman, A. (2008). The effects of age, birth cohort and survey period on leisuretime physical activity by Australian adults: 1990-2005. British Journal of Nutrition, 101(4), 609-617.

Barrows, P.L. (2003). Exercise participation and the relationship to depressive symptomatology, motives, barriers, and perceived benefits of exercise participation in college students. Dissertation Abstract International, 64(3-B), 1477.

Bauman, A., Bull, F., Chey, T., Craig, C.L., Ainsworth, B.E., Sallis, J.F., Bowles, HR, Hagstromer, M., Sjostrom, M., Pratt, M. \& The IPS Group. (2009). The international prevalence study on physical activity: results from 20 countries. International Journal of Behavioral Nutrition and Physical Activity, 6(21), 1-11.

Bloemhoff, H.J. (2010). Gender- and race-related physical activity levels of South African university students. African Journal for Physical, Health Education, Recreation and Dance, 16(4), 25-35.

Brown, S.A. (2005) Measuring perceived benefits and perceived barriers for physical activity. American Journal of Heath Behavior, 29(2), 107-116.

Brown, J.D. \& Siegal, J.M. (1988). Exercise as a buffer of life stress: a prospective study of adolescent health. Health Psychology, 7(4), 341-353.

Brown, W.H., Pfeiffer, K., Mclver, K.L., Dowda, M., Almeida, J. \& Pate, R. (2006). Assessing preschool children's physical activity: An Observational System for Recording Physical Activity in Children-Preschool Version (OSRAC-P). Research Quarterly for 
Exercise and Sport, 77(2), 167-176.

Brownson, R.C, Eyler. A.A., King, A.C., Brown, D.R., Shyu, Y.L. \& Sallis, J.F. (2000). Patterns and correlates of physical activity among women ages 40 years and older in the United States. American Journal of Public Health, 90, 264-270.

Caspersen, C.J, Powell, K.E. \& Christensen, G.M. (1985). Physical activity, exercise and physical fitness: definitions and distinctions for health-related research. Public Health Reports, 100, 126-131.

Craig, C.L., Marshall, A.L., Sjöström, M., Bauman, A.E., Booth, M.L., Ainsworth, B.E., Pratt, M., Ekelund, U., Yngve, A., Sallis, J.F. \& Oja, P. (2003). International Physical Activity Questionnaire: 12-Country Reliability and Validity. Medicine and Science in Sports and Exercise, 35(8), 1381-1395.

Dietz, W.H. (1998). Health consequences of obesity in youth: childhood predictors of adult disease. Pediatrics, 101, 518-525.

Dunn, M.S. \& Wang, M.Q. (2003). Effects of physical activity on substance use among college students. American Journal of Health Studies, 18(2/3), 126-132.

Eyler, A.A., Baker, E., Cramer, L., King, A.C., Brownson, R.C. \& Donatelle, R.I. (1998). Physical activity and minority women: A qualitative study. Health Education and Behavior, 25, 640-652.

Godin, G., Desharnais, R., Valois, P., Lepage, L., Jobin, J. \& Bradet, R. (1994). Differences in perceived barriers to exercise between high and low intenders: observations among different populations. Am J Health Promotion, 8, 279-284.

Haase, A., Steptoe, A., Sallis, J.F. \& Wardle, J. (2004). Leisure time physical activity in university students from 23 countries: associations with health beliefs, risk awareness and national economic development. Preventive Medicine, 39, $182-190$.

IPAQ Research Committee. (2005). Guidelines for data processing and analysis of the International Physical Activity Questionnaire (IPAQ): short and long forms (online), at http://www.ipaq.ki.se/scoring.pdf. June 2014.

Irwin, J.D. (2004). Prevalence of university students' sufficient physical activity: a systematic review. Perception and Motor Skills, 98, 927-943.

Johnson Controls. (2010). Global Workplace Innovation (online) at, http://www.johnsoncontrols.com/content/dam/WWW/jci/be /global workplace innovation/oxygenz/Oxygenz Report - 2010.pdf. July 2014.

Kaplan, G.A., Strawbridge, W.J., Richard D. Cohen,R.D. \& Hungerford, L.R. (1996). Natural history of leisure-time physical activity and its correlates: associations with mortality from all causes and cardiovascular disease over 28 years. American Journal of Epidemiology 144(8):793-797.

Keating, X.D., Guan, J., Pinero, J.C. \& Bridges, D.M. (2005). A meta-analysis of college students' physical activity behaviors. Journal of American College Health, 54(2), 116-125.

King, A.C., Castro, C., Wilcox, S., Eyler, A.A., Sallis, J.F.\& Brownson, R.C. 2000. Personal and environmental factors associated with physical activity among different racial-ethnic groups of US middle-age and older-age women. Health Psychology 19, 354-364.

Kujala, U.M., Kaprio, J., Sarna, S. \& Koskenvuo, M. (1998). Relationship of leisure-time physical activity and mortality: the Finnish twin cohort. JAMA, 279(6), 440-444.

Leslie, E., Owen, N., Salmon, J., Bauman, A., Sallis, J.F. and Kai Lo, S. (1999). Insufficiently active Australian college students: perceived personal, social and environmental influences. Preventive Medicine, 28, 20-27.

Lovell, G.P.,Ansari, E.W., Parker, J.K. (2010). Perceived exercise benefits and barriers of non-exercising female university students in the United Kingdom. Int J Environ Res Public Health,7,784-98.

Martínez-Lemos, R.I., Puig-Ribera, A.M., García-García, O. (2014). Perceived barriers to physical activity and related factors in spanish university students. Open Journal of Preventive Medicine, 4, 164-174.

McCrindle, M., Wolfinger, E. (2008). The ABC of XYZ: Understanding the global generations. Sydney: University of New South Wales Press Ltd.

Paffenbarger R.S., Jr, Hyde R.T., Wing A.L., Lee I.M., Jung D.L. \& Kampert J.B. (1993). The association of changes in physical-activity level and other lifestyle characteristics with mortality among men. New England Journal of Medicine, 328(8):538-545.

Pengpid, S. \& Peltzer, K. (2013). Physical inactivity and associated factors among university students in South Africa. African Journal for Physical, Health Education, Recreation and Dance (AJPHERD), 19(1), 143-153.

Princeton One (2008). Understanding Generation Y: What you need to know about the Millennials (online), at http://www.princetonone. com/news/PrincetonOne\%20White\%20Paper2.pdf. July 2014.

Riddoch, C. (2005). Physical activity. In: L. Ewles (ed), Key topics in public health: essential briefings on prevention and health promotion (pp 103-118). Edinburgh: Elsevier Churchill Livingstone.

Ravussin, E. (1995). Obesity in Britian: rising trend may be due to 'pathoenvironment'(letter). British Medical Journal, 311 (7019):15691569.

Sallis, J.F. (1999). Influences on physical activity of children, adolescents, and adults. pp. 27-32. In C.B. Corbin and R.P. Pangrazi (Eds.), Toward a better understanding of physical fitness and activity. Scottsdale, AZ: Holcomb Hathaway.

Sallis, J.F., Prochaska, J.J. \& Taylor, W.C. (2000). A review of correlates of physical activity of children and adolescents. Medicine \& Science in Sports \& Exercise, 32, 963-975.

Salmon, J., Owen, N., Bauman, A., Schmitz, M.K.H., Booth, M. (2000). Leisure-time, occupational, and household physical activity among professional, skilled, and less-skilled workers and homemakers. Preventive Medicine, 30: 191-199.

Santos R, Silva P, Santos P, Ribeiro JC, Mota J. (2008). Physical activity and perceived environmental attributes in a sample of Portuguese adults: results from the Azorean Physical Activity and Health study. Prev Med, 47: 83-88.

Scheerder, J., Thomis, M., Vanreusel, B., Lefevre, J., Renson, R., Vanden Eynde, B. \& Beunen, G. (2006). Sports participation among females from adolescence to adulthood. A longitudinal study. International Review for the Sociology of Sport, 41, 413-430. 
Sechrist, K.R., Walker, S.N. \& Pender, N. J. (1987). Development and psychometric evaluation of the exercise benefits/barriers scale. Research in Nursing and Health, 6(10), 357-365.

Shaw, B.A., Spokane, L.S. (2008). Examining the association between education level and physical activity changes during early old age. J Aging Health, 20(7), 767-787.

Shoji, H., Hamada,S. \& Mano, Y. (2013). Perceived benefits and barriers to sports activities among Japanese young adults aged 20-39. Europian Associatin for Sport and Management (EASM) (online) at http://easm.net/download/2013/PERCEIVED\%20 BENEFITS\%20AND\%20BARRIERS\%20TO\%20SPORTS\%20ACTIVITIES\%20AMONG\%20JAPANESE\%20YOUNG\%20ADULT S\%20AGED\%2020.pdf. June 2014.

Sotade, O. (2011). Is Gen Y Tech-Savvy or Tech-Dependent?(online), at http://healthculturesociety.wikispaces.com/ls+Gen+Y+TechSavvy+or+Tech-Dependent\%3F. July 2014.

Thijssen, D.H., Maiorana, A.J, O'Driscoll, G., Cable, N.T., Hopman, M.T. \& Green, D.J. (2010). Impact of inactivity and exercise on the vasculature in humans. Eur J Appl Physiol, 108, 845-875.

Thornórarinsson ET1, Harðarson T, Sigvaldason H, Sigfússon N. (2002). The relationship between educational level, physical activity and mortality.] Laeknabladid; 88(6):497-502.

Trost, S.G., Owen, N., Bauman, A.E., Sallis, J.F. \& Brown, W. (2002). Correlates of adults participation in physical activity: review and update. Medicine and Science in Sports and Exercise, 34(12), 1996-2001.

Varela, V., Cancela, J.M., Ayán, C., Martín, V. \& Molina, A. (2012). Lifestyle and health among Spanish University Students: differences by gender and academic discipline. International Journal of Environmental Research and Public Health, 9, 2728-2741.

Yarrow, K., \& O'Donnell, J. (2009). Gen buy: How tweens, teens, and twenty something are revolutionizing retail. San Francisco, CA: Jossey Bass Publishers.

Zunft, H.J.F., Friebe, D., Seppelt, B., Widhalm, K., Remaut de Winter, A.M, Vaz de Almeida, M.D., Kearney, J.M. \& Gibney, M. (1999). Perceived benefits and barriers to physical activity in a nationally representative sample in the European Union. Public Health Nutrition, 2(1a), 153-160. 